University of Massachusetts Amherst

ScholarWorks@UMass Amherst

1998

\title{
Analytical selenoamino acid studies by chromatography with interfaced atomic mass spectrometry and atomic emission spectral detection
}

PC Uden

SM Bird

M Kotrebai

P Nolibos

JF Tyson

See next page for additional authors

Follow this and additional works at: https://scholarworks.umass.edu/chem_faculty_pubs

\section{Recommended Citation}

Uden, PC; Bird, SM; Kotrebai, M; Nolibos, P; Tyson, JF; Block, E; and Denoyer, E, "Analytical selenoamino acid studies by chromatography with interfaced atomic mass spectrometry and atomic emission spectral detection" (1998). FRESENIUS JOURNAL OF ANALYTICAL CHEMISTRY. 1060.

Retrieved from https://scholarworks.umass.edu/chem_faculty_pubs/1060 
Authors

PC Uden, SM Bird, M Kotrebai, P Nolibos, JF Tyson, E Block, and E Denoyer 
Peter C. Uden · Susan M. Bird • Mihaly Kotrebai

Paula Nolibos · Julian F. Tyson · Eric Block

Eric Denoyer

\section{Analytical selenoamino acid studies by chromatography with interfaced atomic mass spectrometry and atomic emission spectral detection}

Received: 16 February 1998

\begin{abstract}
Consumption of selenium enriched plants or yeast-based nutritional supplements has been reported to provide anticarcinogenic benefits which are selenium compound dependent. Separation and identification of these selenium compounds is critical to understand the activity. Plants and yeast convert inorganic selenium in the soil or growth media into organoselenium compounds, probably following a route similar to the sulfur assimilatory pathway. Non-volatile selenium compounds produced include selenoamino acids, some of which have shown anticarcinogenic activity. Volatile compounds produced by chemical reaction of involatile precursors have also been found. An ion pair chromatographic method with ICP-MS detection for the separation of selenoamino acid standards potentially present in real samples is given. The method allows separation of selenoamino acids including such analytes as the cis-trans isomers of Se-1propenyl-DL-selenocysteine. The method also provides the capability of determining the presence of selenoxides and possibly selenones, and tracking of other functionalities and reactions by selective derivatization. Alternatively, selenoamino acids are treated with ethylchloroformate to produce stable volatile derivatives which are amenable to GC separation with element specific atomic emission detection (GC-AED). Results of total selenium determination and speciation of selenium enriched yeastbased nutritional supplements, selenium enriched allium vegetables and bioremediation samples are presented.
\end{abstract}

P. C. Uden $(\bowtie) \cdot$ S. M. Bird · M. Kotrebai · P. Nolibos J. F. Tyson

Department of Chemistry,

Lederle Graduate Research Tower A

University of Massachusetts, Box 35410, Amherst,

MA 01003-4510, USA

E. Block

Department of Chemistry, SUNY-Albany, Albany, NY 12222, USA

E. Denoyer

The Perkin-Elmer Corporation, 761 Main Ave., Norwalk, CT 06859, USA

\section{Introduction}

Trace element analytical techniques are essential to obtain environmentally, biologically and clinically significant data for total element determinations, but it is clear that understanding the nutritional, toxicological and biochemical impact of any element on a biological system depends on the different elemental forms present, their relative quantities and chemical interactions. Speciation studies must be coordinated with selective detection and correlated total trace element measurements.

Selenium is an essential element which is nevertheless toxic above a rather narrow range of adequacy [1]. The nutritional bioavailability [2], toxicity [3, 4] and cancer chemopreventive properties $[2,5]$ of selenium are chemical species dependent. Selenium-enriched yeast is used as a selenium source in nutritional supplements and its consumption has been found to be associated with statistically significant reductions in cancer mortality and total cancer incidence [5]. Selenium deficiency will cause skeletal and cardiac muscle dysfunction $[6,7]$ and the element is known to prevent cell membranes from oxidative damage $[8,9]$. The early literature contains claims that selenite and selenate may have mutagenic effects $[10,11]$.

Selenoamino acids have been shown to be important with respect to bioavailability. Virtanen discovered that the selenoamino acids selenocystine $\left(\left(\mathrm{HOOCCH}\left(\mathrm{NH}_{2}\right) \mathrm{CH}_{2} \mathrm{Se}\right)_{2}\right)$ and selenomethionine ( $\left.\mathrm{HOOCCH}\left(\mathrm{NH}_{2}\right) \mathrm{CH}_{2} \mathrm{CH}_{2} \mathrm{SeMe}\right)$ were present in onion [12] and it is suggested that there may be a Se based flavor chemistry in Allium spp. parallel to that of sulfur. The very low odor threshold of low molecular weight Se compounds may counterbalance the much lower natural levels of Se than sulfur $(10,000$ fold or more).

Chromatographic separation and speciation of organic and inorganic selenium compounds has followed parallel paths for volatile and non-volatile species. Volatile compounds such as dimethyl selenide, dimethyl diselenide and methaneselenol have been determined by gas chromatography (GC) $[13,14]$. A particularly powerful ana- 


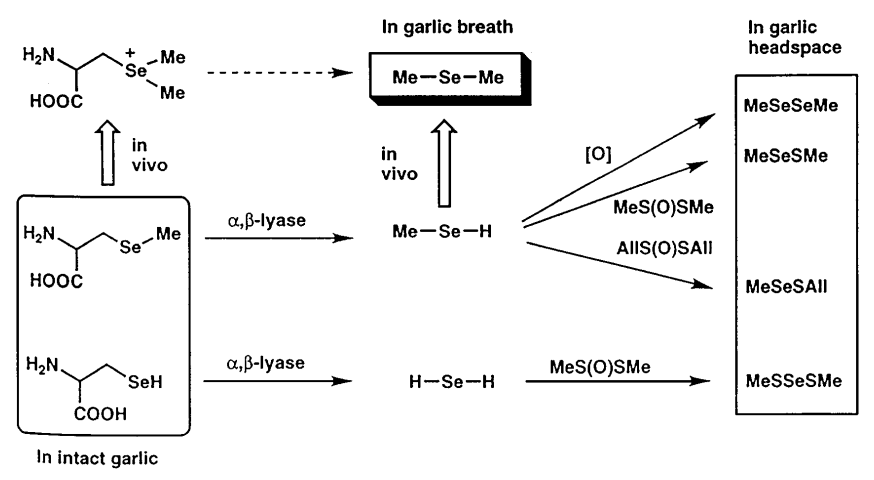

Fig. 1 Proposed enzymatic cleavage of selenoamino acids to give volatile, low-molecular weight organoselenium compounds

lytical approach to low level determination employs headspace-capillary GC and element selective detection by atomic plasma emission spectroscopy (GC-AED) [15, 16]. Even in such selenium-rich plants as garlic (Allium, sativum) high levels of analogous sulfur species are present and element selective detection is valuable in differentiating species by element content. Thus 'selenium breath' following ingestion of garlic has been successfully monitored [17]. GC of selenoamino acids has been carried out by derivatization to volatile species using ethyl chloroformate followed by element selective GC-AED [18]. Figure 1 shows a proposed enzymatic cleavage of selenoamino acids to give volatile, low molecular weight organoselenium compounds [19].

Other nonvolatile selenium species which may be present are selenoxides of selenoamino acids. Analogous sulfoxides are known to be present in Allium species [20]. Wrench has reported the presence of selenomethionine selenoxide in marine phytoplankton, determined by elution similarity to the methionine sulfoxide analog [21]. Bottino et al. suggested the presence of Se-methyl-DL-selenocysteine selenoxide and selenone in marine algae, determined by similar retention (ion exchange) and similar mobility (thin layer chromatography) to the sulfur analogs [22]. The only report of the presence of selenoxides in plants was made by Spare et al., tentatively identifying the presence of Se-methyl-DL-selenocysteine-selenoxide, Se[ $\beta$-carboxypropyl]-selenocysteine selenoxide, and $\gamma$-glutamyl-Se-DL-propenyl-selenocysteine [12].

Various modes of liquid chromatography, ion exchange, ion pair and reverse phase partition with derivatization have been used for separation of inorganic selenium species and selenoamino acids [23-32]. Selenite and selenate are typically separated on a strong anion exchange column $[23,24]$. The trimethylselenonium cation has been included in such separations, eluting in the dead volume, low ng detection being reported by hydride generation or electrothermal atomic absorption spectrometric detection of Se [24, 25]. Selenocystine and selenomethionine have been similarly separated with electrothermal atomic absorption spectrometric detection, but selenite and selenate were poorly resolved and interfered with amino acid determination [26].
The inductively coupled plasma mass spectrometer (ICP-MS ) is an effective element specific HPLC detector which has been applied to a number of selenium speciation studies [22, 33-39]. In this paper, as part of an ongoing study of the cancer chemopreventive activity of selenium, extracts of selenium containing samples are analyzed by HPLC-ICP-MS and by chloroformate derivatization GC-AED. Total selenium levels are determined and selenoamino acid and selenoxide levels and reaction chemistry are reported.

\section{Experimental}

Instrumentation

An Elan 5000 inductively coupled plasma mass spectrometer (Perkin-Elmer Sciex, Norwalk, CT USA) was used for total selenium determination and HPLC-ICP-MS. Samples were introduced using a cross flow nebulizer and double pass spray chamber. For chromatographic detection the ICP-MS parameter settings were as follows: forward power $1003 \mathrm{~W}$; plasma Ar flow $15 \mathrm{~L} / \mathrm{min}$; auxiliary Ar flow $0.8 \mathrm{~L} / \mathrm{min}$; nebulizer flow $0.925 \mathrm{~L} / \mathrm{min}$; nickel sampler and skimmer cones; normal resolution; peak hop mode; dwell time $500 \mathrm{~ms}$, and mass 82 monitored. For total selenium determination ${ }^{82} \mathrm{Se}$ and ${ }^{77} \mathrm{Se}$ were monitored with ${ }^{74} \mathrm{Ge}$ as an internal standard using a $250 \mathrm{~ms}$ dwell time (n 27); isobaric interference from ${ }^{74} \mathrm{Se}$ is automatically corrected in the software, as has been confirmed in the results for certified materials. The chromatographic system consisted of an HP1090 liquid chromatograph (Hewlett Packard, Wilmington, DE USA) and a Zorbax SB-C8 column $(4.6 \mathrm{~mm} \times 15 \mathrm{~cm})$ preceded by a Zorbax SB-C8 guard column $(4.0 \mathrm{~mm} \times 12.5 \mathrm{~mm})($ MAC-MOD Analytical, Chadds Ford, PA, USA). A piece of $30 \mathrm{~cm}$ long PEEK $^{\circledR}$ tubing $(0.25 \mathrm{~mm}$ i.d.) was used to transfer the column eluent to the nebulizer. The optimized mobile phase composition was $98 / 2$ water/methanol with $0.1 \%$ trifluoroacetic acid. The mobile phase flow rate was typically $1.0 \mathrm{~mL} / \mathrm{min}$ and the sample injection volume was $10 \mu \mathrm{L}$.

A Hewlett-Packard HP 5921A atomic emission detector (AED) interfaced with an HP 5890II gas chromatograph was used. The injection port (splitless) was maintained at $250^{\circ} \mathrm{C}$ : the $\mathrm{GC}$ oven was programmed from $100^{\circ} \mathrm{C}$ (initial temperature for $5 \mathrm{~min}$ ) to $200^{\circ} \mathrm{C}$ at $5^{\circ} \mathrm{C} / \mathrm{min}$, holding at $200^{\circ} \mathrm{C}$ for $5 \mathrm{~min}$. An HP-1 $25 \mathrm{~m} \times 0.32 \mathrm{~mm} \times$ $0.17 \mu \mathrm{m}$ (film thickness) column was used. The helium plasma gas flow was kept at $180 \mathrm{~mL} / \mathrm{min}$. The GC-AED used hydrogen as reagent gas, with detection at $193.1 \mathrm{~nm}(\mathrm{C})$ and $196.1 \mathrm{~nm}(\mathrm{Se})$.

\section{Chemicals}

Barnstead (Boston, MA USA) E-pure 18 mOhm water, nitric acid and hydrochloric acid (Certified ACS Plus, Fisher Scientific Co., Fair Lawn, NJ, USA), nitric acid purified by sub-boiling, trifluoroacetic acid (Aldrich, Milwaukee, WI, USA) and methanol (HPLC grade), ethanol, pyridine, chloroform, $30 \%$ hydrogen peroxide, $3.2 \%$ hydrogen peroxide, sodium thiosulfate pentahydrate, and sodium carbonate decahydrate, (Certified ACS grade) (Fisher Scientific Co.), CFA-C (mixture of amines, Spectrasol, Inc., Warwick, NY) were used for sample or mobile phase preparation, or in oxidation reactions.

Sodium selenate, DL-selenomethionine, DL-selenoethionine, DL-selenocystine, Protease XIV, and ethyl chloroformate (ECF) were obtained from Sigma Chemical Company (St. Louis, MO, USA). Se-methyl-DL-selenocysteine, Se-propyl-DL-selenocysteine, and Se-allyl-DL-selenocysteine were obtained from Dr. Howard Ganther (University of Wisconsin, Madison, WI, USA); cis/transSe-1-propenyl-DL-selenocysteine was synthesized in-house. Plasma selenium and germanium standard solutions $(1000 \mu \mathrm{g} / \mathrm{mL})$ were obtained from Spex Industries Inc., Edison, NJ, USA. Sele- 
nium-enriched yeast was obtained from Nutrition 21 (San Diego, CA, USA), Dr. Helen Crews (Ministry of Agriculture, Fisheries and Food, Norwich, UK), and Dr. Richard Zitomer (State University of New York, Albany, NY, USA). Freeze-dried selenium enriched garlic and onion (A.cepa) samples $(1355 \mu \mathrm{g} / \mathrm{g}, 296 \mu \mathrm{g} / \mathrm{g}$, $235 \mu \mathrm{g} / \mathrm{g}$ and $140 \mu \mathrm{g} / \mathrm{g}$ selenium on a dry weight basis) were obtained from Dr. Clement Ip (Roswell Park Cancer Institute, Buffalo, NY). Phytoremediation samples of Brassica juncea (s1), manure from animals fed alfalfa without selenium (s2), manure from animals fed alfalfa with selenium (s3), manure from animals fed the mixture Astragolus praelongus and alfalfa without selenium (s4), a mixture of Astragolus Praelongus and alfalfa without selenium (s5), alfalfa with selenium (s6) and alfalfa without Se (s7) were obtained from Dr. Gary S. Bañuelos (USDA, Fresno, CA, USA). NIST SRM 1566 Oyster Tissue (O.T. 1566), NIST SRM 1570a Spinach Leaves (Spinach) and NRCC CRM DOLT1 (DOLT 1) were used for method validation.

Stock solutions of selenoamino acids were prepared in $0.2 \mathrm{M}$ $\mathrm{HCl}$. A stock solution of selenate was prepared in $2 \%(\mathrm{v} / \mathrm{v}) \mathrm{HNO}_{3}$, while the plasma selenium standard was used as a stock solution of selenite. Working solutions were diluted with mobile phase and stored in the dark between $0-4{ }^{\circ} \mathrm{C}$. The standards used in measurements thus were $0.02-0.002 \mathrm{M}$ in $\mathrm{HCl}$ or $0.0002 \%$ in $\mathrm{HNO}_{3}$ after dilution, these acid concentrations having no effect on chromatographic separation and speciation considering the $10 \mu \mathrm{L}$ volumes injected.

\section{Sample preparation}

\section{Total selenium determination}

The total selenium concentrations of the Standard and Certified Reference Materials and of the samples used in the selenium mass balance study were determined by the following method. Freezedried, powdered samples (0.1-0.2 g) were measured into a microwave vessel. Five $\mathrm{mL}$ of distilled concentrated $\mathrm{HNO}_{3}$ and $1 \mathrm{~mL}$ of $2.5 \mu \mathrm{g} / \mathrm{mL}$ germanium internal standard were added to each sample. The vessels were then covered and left overnight. The next day $2 \mathrm{~mL}$ of $30 \% \mathrm{H}_{2} \mathrm{O}_{2}$ and $2 \mathrm{~mL}$ of water were added to the sample. The samples were then digested using a high-pressure closedvessel microwave digestion system (Q Max 4000, Questron Corporation, Princeton, NJ, USA) using a 7 step timed pressure program which had a maximum pressure of $140 \mathrm{psi}$, a temperature limit of $180^{\circ} \mathrm{C}$ and a total digestion time of $60 \mathrm{~min}$. The digested samples were transferred to $50 \mathrm{~mL}$ centrifuge tubes and diluted with $18 \mathrm{mOhm}$ water to $25 \mathrm{~mL}$. The digestion was repeated three times for each sample to ensure proper sampling. Initial reproducibilities obtained showed that the Astralagus Prelongus needed additional grinding and thus $2 \mathrm{~g}$ of the sample was placed in a $60 \mathrm{~mL}$ plastic bottle along with 5 methacrylate pestle balls (Spex Industries, Part 8002). The sample was ground for $1 \mathrm{~h}$ in a mixer mill (Model 800, Spex Industries). Three replicate samples were digested from the ground sample. Selenium was determined in the resulting solutions by ICP-MS using a standard addition method after an appropriate dilution. These dilution factors were determined by separate measurements involving regular calibration. The monitored isotopes were $\mathrm{Se}^{77}$ and $\mathrm{Se}^{82}$. The germanium internal standard, added to the samples before the digestion, was used to correct for the loss during the sample transfer, the dilution errors and the instrument drift. The standard addition used a five-point calibration: blank, sample, sample + std1, sample + std 2 and sample + std3. The lower concentration samples were measured using a standard set of 10,20 and $50 \mathrm{ng} / \mathrm{mL}$, the higher concentration samples using a set of 50, 200 and $500 \mathrm{ng} / \mathrm{mL}$ Se. All sample preparation was carried out in a Class- 100 clean room. To conform with good laboratory practice and avoid any cross contamination of low-Se samples from high-Se samples, all the glassware, plastic ware and microwave vessels were leached in $10 \% \mathrm{v} / \mathrm{v}$ nitric acid for $24 \mathrm{~h}$, then rinsed three times with distilled deionized water before use. In addition the microwave vessels were cleaned in a blank microwave run with $10 \mathrm{~mL}$ sub-boiled nitric acid after every three digestions. A typical microwave run included up to 8 samples, two SRMs and two method blanks.

\section{Extraction/mass balance}

\section{Phytoremediation samples}

Results from three different extraction methods are reported. Typical procedures are noted as follows.

Extraction $1(\mathrm{e} 1): 5 \mathrm{~mL}$ of a 9:1 mixture of $0.1 \mathrm{M} \mathrm{HCl}$ and $95 \%$ ethanol was added to a $0.2 \mathrm{~g}$ sample in a $15 \mathrm{~mL}$ centrifuge tube and the mixture was shaken for $4 \mathrm{~h}$ at room temperature using a wristaction shaker (Burrell, Pittsburgh, PA, USA).

Extraction 2 (e2): $5 \mathrm{~mL}$ of distilled deionized water was added to a $0.2 \mathrm{~g}$ sample in a $15 \mathrm{~mL}$ centrifuge tube and the tube was placed in a double boiling water bath for $1 \mathrm{~h}$. The mixture was shaken well every $15 \mathrm{~min}$.
Fig. 2 Selenium content of the extracts after extraction $(1)$, after filtration through $0.45 \mu \mathrm{m}$ syringe filter (2), after filtration through 10,000 MW cut off filter (3), and column recovery (4) expressed in percentage of the total selenium content. (e2: extraction id. 2, s1: sample id. 1)

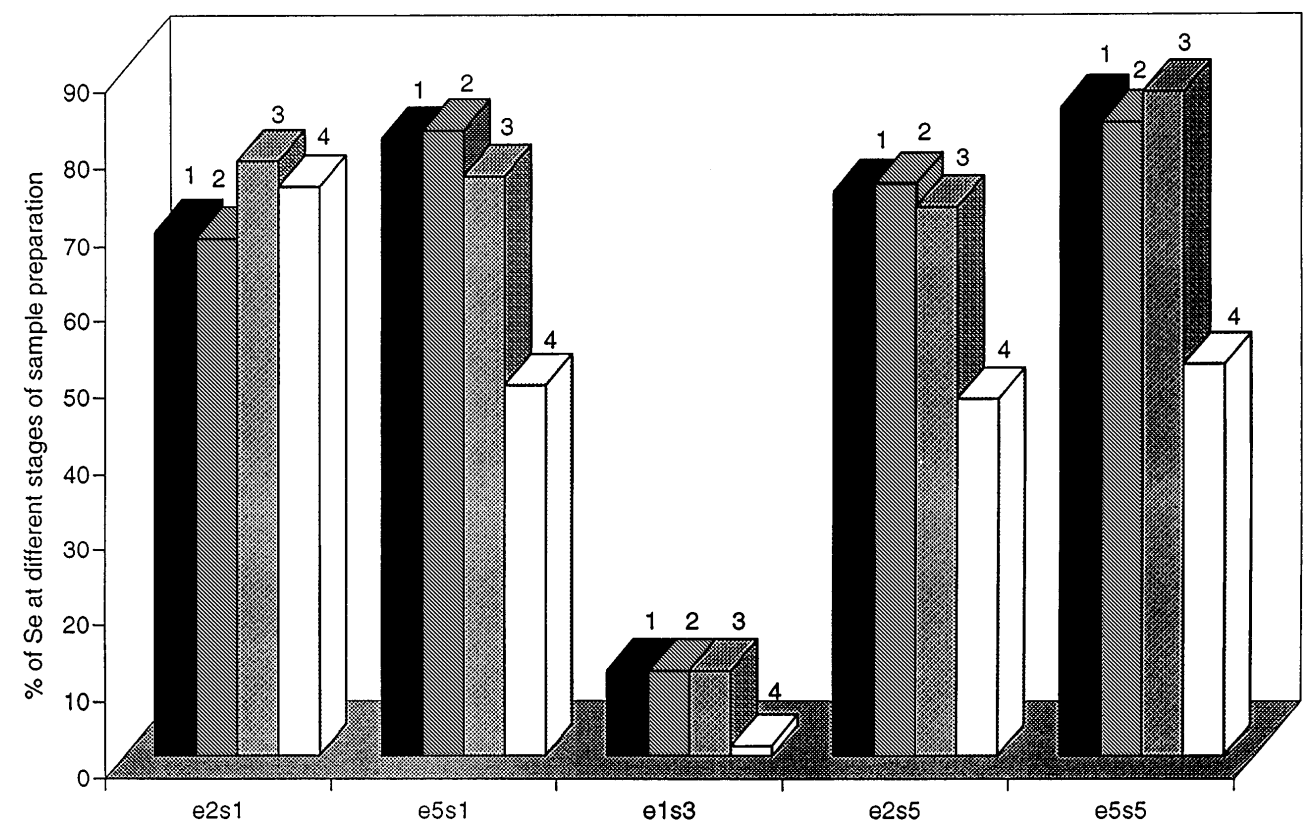


Extraction 5 (e5): $5 \mathrm{~mL}$ of distilled deionized water was added to a $0.2 \mathrm{~g}$ sample and $0.02 \mathrm{~g}$ of Protease XIV enzyme in a $15 \mathrm{~mL}$ centrifuge tube, then the mix was shaken for $24 \mathrm{~h}$ at room temperature using the wrist-action shaker.

Before each extraction the weights of the centrifuge tubes used were measured and noted. After the extraction the samples were centrifuged for 20 min using a Beckman GPR centrifuge (Fullerton, CA, USA) at $3000 \mathrm{G}$. $0.5 \mathrm{~mL}$ of the supernatant was pipetted from each sample to a separate tube for total selenium determination. The rest of the supernatant was filtered through a $0.45 \mu \mathrm{m}$ polypropylene filter (Arbor Technologies, Ann Arbor, MI, USA). The weights of the centrifuge tubes containing the sample and the leftover extract were measured again, providing the amount of the extract left in the tube. A $0.5 \mathrm{~mL}$ portion of the extract was pipetted into a separate tube for total selenium determination. The rest of the filtered extract was filtered again using a 10,000 Da molecular weight cutoff filter (Micron Separations Inc., Westboro, MA, USA) by centrifuging overnight. Subsequent HPLC separation conditions preclude any high molecular weight species eluting from the column and as is shown, quantitation (Fig. 2) shows no selenium loss at this filtration step. A $0.5 \mathrm{~mL}$ extract sample was pipetted into a separate tube for total selenium determination; the rest of the solution was transferred into an HPLC sample vial. The sum of the unextracted selenium content of the original sample plus the selenium content of the leftover extract (all in the $15 \mathrm{~mL}$ centrifuge tubes) was determined by the previously described method (microwave). The selenium content of the extracts (extraction efficiency) at the different steps was determined from the $0.5 \mathrm{~mL}$ separated solutions, without microwave digestion. A $0.2 \mathrm{~mL}$ sample was diluted with $0.8 \mathrm{~mL}$ water and $1 \mathrm{~mL} 20 \%$ CFA-C solution containing $100 \mathrm{ng} / \mathrm{g}$ Ge internal standard. The results provided with this method were confirmed by digestion of selected extracts using the microwave method.

\section{Allium and yeast samples}

Allium and yeast samples $(0.3 \mathrm{~g})$ were separately added to $6 \mathrm{~mL}$ of water in a $15 \mathrm{~mL}$ polypropylene centrifuge tube, and heated and shaken in a hot water bath at $85-90^{\circ} \mathrm{C}$ for $1 \mathrm{~h}$. The solutions were then centrifuged for $30 \mathrm{~min}$, supernatant was removed and filtered through a $0.45 \mu \mathrm{m}$ polypropylene filter. Aliquots (three $\mathrm{mL}$ ) of each of the filtered solutions were passed through 10,000 Da molecular weight cutoff filters by centrifuging overnight. Solutions $(0.45 \mathrm{~mL})$ were then spiked with $50 \mu \mathrm{L}$ of a $10 \mu \mathrm{g} / \mathrm{mL}$ DL-selenoethionine solution before being chromatographed.

\section{Oxidation}

To 1-2 $\mathrm{mL}$ of each of seven selenoamino acid stock solutions ( $4 \mu \mathrm{g} / \mathrm{mL}$ Se to $94 \mu \mathrm{g} / \mathrm{mL} \mathrm{Se}$ ), $0.1 \mathrm{~mL}$ of $30 \%$ hydrogen peroxide was added. After mixing, the solutions were left overnight. Solutions were then diluted with mobile phase, and a mixture of the seven oxidized amino acids prepared and chromatographed. For the study of the reversible oxidation of DL-selenomethionine, three samples were investigated. Firstly, $0.5 \mathrm{~mL}$ of a stock solution in $\mathrm{HCl}$ containing $42 \mu \mathrm{g} / \mathrm{mL}$ of selenium was diluted to $10 \mathrm{~mL}$ with mobile phase. Secondly, $60 \mu \mathrm{L}$ of $0.032 \%$ hydrogen peroxide, prepared by diluting $3.2 \%$ hydrogen peroxide, was added to $0.5 \mathrm{~mL}$ of $42 \mu \mathrm{g} / \mathrm{mL}$ selenium stock solution and diluted to $10 \mathrm{~mL}$ with mobile phase. Thirdly, $60 \mathrm{~mL}$ of $0.032 \%$ hydrogen peroxide was added to $0.5 \mathrm{~mL}$ of $42 \mu \mathrm{g} / \mathrm{mL}$ (Se) stock solution, and then after $30 \mathrm{~min} 1.5 \mathrm{~mL}$ of $0.005 \mathrm{M}$ sodium thiosulfate, adjusted to $\mathrm{pH}>7$ with sodium carbonate, was added and the mixture diluted to $10 \mathrm{~mL}$ with mobile phase.

\section{Esterification}

\section{$H P L C$}

Sample portions $(0.5 \mathrm{~mL})$ were pipetted into four $1.5 \mathrm{~mL}$ centrifuge tubes. Samples \#2, \#3 and \#4 were dried at $40^{\circ} \mathrm{C}$ under vacuum using a Bio-Rad Speed Vac (Richmond, CA, USA). Sample \#1 was retained in its original form as reference. Sample \#2 was dissolved in the $0.5 \mathrm{~mL}$ HPLC mobile phase to serve as a secondary reference. The esterification was done on samples \#3 and \#4 by adding $0.5 \mathrm{~mL}$ dried and filtered methanol or ethanol containing 3\% (v/v) sulfuric acid. The samples were left at room temperature for $24 \mathrm{~h}$ prior to the analysis by HPLC-ICP-MS.

\section{Gas chromatography}

The derivatization procedure was adapted from that of Husek [40]. DL-selenomethionine $(1.7 \mathrm{mg})$, DL-selenoethionine $(1.1 \mathrm{mg})$, Se-allyl-DL-selenocysteine $(410 \mu \mathrm{g} / \mathrm{mL})$, Se-propyl-DL-selenocysteine $(1026 \mu \mathrm{g} / \mathrm{mL})$ and Se-methyl-DL-selenocysteine $(7516 \mu \mathrm{g} / \mathrm{mL})$ $(10 \mathrm{~mL}$ of each solution) were added to each vial and treated with $100 \mu \mathrm{L}$ of $\mathrm{H}_{2} \mathrm{O}$ :EtOH:pyridine mixture $(60: 32: 8)$ in $2 \mathrm{~mL}$ vials. Ethyl chloroformate (ECF) $(5 \mu \mathrm{L})$ was added to each vial. After gas evolution ceased, $500 \mu \mathrm{L}$ of chloroform with $1 \%$ ECF were added to each vial. The organic phase was extracted and evaporated to dryness under nitrogen and redissolved with $100 \mu \mathrm{L}$ of chloroform. Aliquots $(1 \mu \mathrm{L})$ of each sample solution were injected into the GC-AED. Aliquots $(10 \mu \mathrm{L})$ of the chloroform solution for each vial were mixed in a new vial to comprise a selenoamino acid solution, and $1 \mu \mathrm{L}$ of the solution was injected into the GC-AED.

\section{Results and discussion}

\section{Total selenium}

For the determination of total selenium, the method involved microwave digestion of biological samples using concentrated $\mathrm{HNO}_{3}$. Solutions prepared by this method were suitable for ICP-MS measurements. Standard addition was necessary, due to the uncertainty of the amount of remaining unreacted acid. Experiments proved that the internal standard did not correct the selenium signal fluctuation well, due to the difference in acid content between the samples and the standard. These differences were much larger than could have been caused by the contribution of ${ }^{74} \mathrm{Se}$. Instrument detection limits $(3 \sigma$-standard deviation of the blank) were found to be $0.2 \mathrm{ng} / \mathrm{mL}$ for ${ }^{77} \mathrm{Se}$ and ${ }^{82} \mathrm{Se}$. Based on the results for the Standard Reference Materials listed in Table 1, it can be concluded that the total selenium determination method works well for concentrations higher than $2 \mu \mathrm{g} \mathrm{Se} / \mathrm{g}$ sample. The $0.122 \mu \mathrm{g}$ $\mathrm{Se} / \mathrm{g}$ concentration in the Spinach SRM is lower than the $0.25-0.5 \mu \mathrm{g}$ Se/g sample determination limit of the method. The total selenium concentrations of the samples

Table 1 Total selenium concentrations of standard and certified reference materials determined by the microwave method

\begin{tabular}{llllll}
\hline Sample & $\begin{array}{l}\text { Iso- } \\
\text { topes }\end{array}$ & $\begin{array}{l}\text { Average } \\
\text { ng/g }\end{array}$ & $\begin{array}{l}95 \% \mathrm{C} \text { I } \\
\pm \mathrm{ng} / \mathrm{g}\end{array}$ & $\begin{array}{l}\text { Certified } \\
\mathrm{ng} / \mathrm{g}\end{array}$ & $\begin{array}{l}95 \% \mathrm{C} \mathrm{I} \\
\pm \mathrm{ng} / \mathrm{g}\end{array}$ \\
\hline DOLT 1 & $\mathrm{Se}^{77}$ & 7.1 & 0.3 & 7.34 & 0.42 \\
& $\mathrm{Se}^{82}$ & 7.2 & 0.3 & 7.34 & 0.42 \\
O.T.1566A & $\mathrm{Se}^{77}$ & 2.3 & 0.1 & 2.21 & 0.24 \\
& $\mathrm{Se}^{82}$ & 2.7 & 0.2 & 2.21 & 0.24 \\
Spinach & $\mathrm{Se}^{77}$ & 0.4 & 0.1 & 0.12 & 0.01 \\
& $\mathrm{Se}^{82}$ & 0.5 & 0.3 & 0.12 & 0.01 \\
\hline
\end{tabular}


Table 2 Total selenium concentrations of samples used in the mass balance study determined by the microwave method

\begin{tabular}{|c|c|c|}
\hline \multicolumn{2}{|c|}{ Samples } & \multirow{2}{*}{$\begin{array}{l}\text { Concen- } \\
\text { tration } \mu \mathrm{g} / \mathrm{g}\end{array}$} \\
\hline ID & Name & \\
\hline S1. & Brassica juncea & $138 \pm 9.6$ \\
\hline $\mathrm{S} 2$. & $\begin{array}{l}\text { Manure from animals fed alfalfa } \\
\text { without selenium }\end{array}$ & $0.3 \pm 0.1$ \\
\hline S3. & $\begin{array}{l}\text { Manure from animals fed alfalfa } \\
\text { with selenium }\end{array}$ & $68.4 \pm 4.7$ \\
\hline S4. & $\begin{array}{l}\text { Manure from animals fed with the mixture } \\
\text { Astragolus praelongus and alfalfa } \\
\text { without selenium }\end{array}$ & $16.7 \pm 0.8$ \\
\hline S5. & $\begin{array}{l}\text { Mixture of Astragolus praelongus and alfalfa } \\
\text { without selenium }\end{array}$ & $517 \pm 29$ \\
\hline S6. & Alfalfa with selenium & $128 \pm 5.7$ \\
\hline S7. & Alfalfa without selenium & $0.3 \pm 0.1$ \\
\hline
\end{tabular}

involved in the selenium mass balance study are reported in Table 2.

Mass balance of selenium through sample preparation

A range of different extraction techniques such as enzymatic, microwave, hot water, acidic and organic mixtures were used. In these extractions there were two different goals. The first was to achieve the maximum extraction efficiency possible and the second was to maintain similar efficiencies among the different samples. The extraction efficiencies were determined without microwave digestion, using an amine mixture (CFA-C), which overcomes the effect of the organic matrix on the Se measurement [41 ]. The quality of these results was checked by the digestion of selected extracts. The two methods showed better than $92 \%$ agreement based upon 20 samples. This was encouraging, given that two completely different sample preparation methods were employed and that a typical certified concentration can encompass a $\pm 7 \%$ interval.

The step by step determination of selenium content in the extract during the extraction procedure and the separation, enabled selenium mass balance to be followed. The changes in selenium concentration during the sample preparation process did not show selenium loss, which proved that the process did not change the selenium content of the extract. The results for selected samples are reported in Fig. 2. This figure also shows column recovery numbers after the HPLC separation. Even in this relatively small group of samples uniform extraction efficiency was not achieved for three or more replicates. The efficiency and column recovery numbers, determined by dividing the integrated chromatographic peak area by the area of the flow injection peak for the same sample, varied over a wide range irrespective of the extraction technique used. The plant and the manure samples were clearly different from each other based on the extraction efficiencies. The extraction efficiencies from manure samples were very low, which could indicate that the samples already went through a very efficient extraction process in the animal's digestion system. Digestion has removed most of the extractable selenium compounds or converted them to insoluble form perhaps firmly bound to an organic fibrous material matrix.

Determination of the selenium content of the 'leftover' extract (sample plus liquid remaining on the sample) allowed completion of the selenium mass balance. In Table 3 , the total selenium concentration (microwave method) was compared with a calculated selenium concentration for selected samples. The calculated selenium concentration is the sum of the extract leftover selenium concentration (microwave method) and the extract selenium concentration (CFA-C method). The overall agreement between the two different total selenium values was $99 \pm 4 \%$ (reflecting a 95\% confidence interval for 15 samples). The use of the CFA-C reagent was extremely successful, replacing the microwave digestion of extract in the total Se determination procedure; using this procedure the Se mass balance did not show any anomalies.

\section{Speciation}

The liquid chromatographic conditions for selenium speciation utilized an ion pair method previously reported
Table 3 Comparison of total (microwave method) and calculated total (microwave plus CFA-C methods) selenium concentrations for selected samples

\begin{tabular}{lllllll}
\hline $\begin{array}{l}\text { Extraction } \\
\text { type }\end{array}$ & Sample & ID & & $\begin{array}{l}\text { Total Se } \\
\mu \mathrm{g} / \mathrm{g}\end{array}$ & $\begin{array}{l}\text { Calculated total Se } \\
\mu \mathrm{g} / \mathrm{g}\end{array}$ & $\begin{array}{l}\text { Total/Calculated } \\
\%\end{array}$ \\
\hline Hot water & Brassica & e2s1 & Se 77 & 138 & 134 & 103 \\
& & & Se 82 & 138 & 134 & 103 \\
Enzymatic & Brassica & e5s1 & Se 77 & 138 & 131 & 106 \\
& & & Se 82 & 138 & 130 & 106 \\
HCl/MeOH & Manure from & e1s3 & Se 77 & 68 & 64 & 105 \\
& alfalfa & & Se 82 & 68 & 63 & 108 \\
Hot water & Alfalfa + & e2s5 & Se 77 & 525 & 521 & 101 \\
& Praelongus & & Se 82 & 517 & 523 & 99 \\
Enzymatic & Alfalfa + & e5s5 & Se 77 & 525 & 528 & 99 \\
& Praelongus & & Se 82 & 517 & 527 & 98 \\
\hline
\end{tabular}




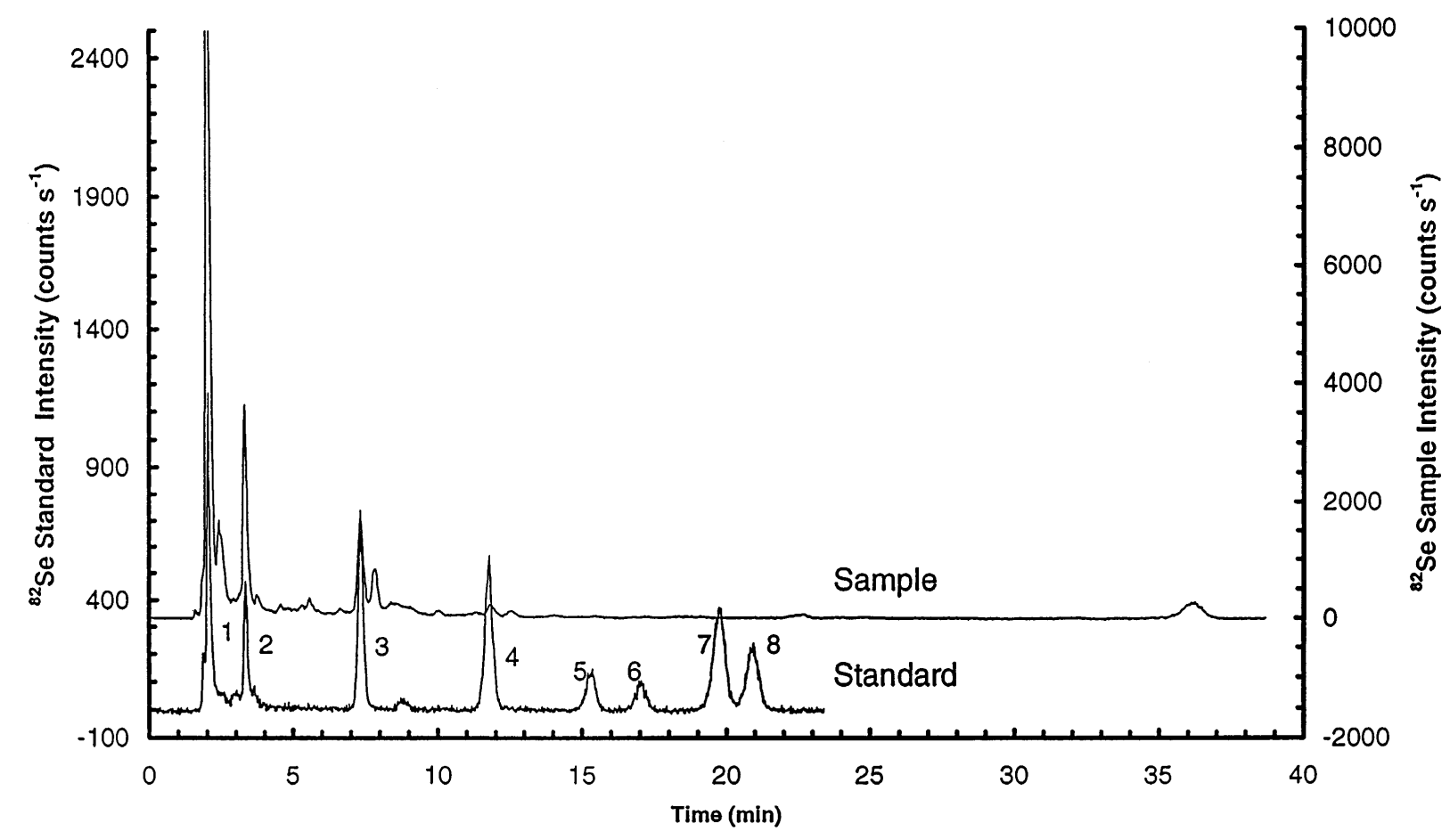

Fig. 3 Ion pair chromatogram of selenoamino acid standard mixture (approximately $300 \mathrm{ng} / \mathrm{g} \mathrm{Se}$ each, enzymatic extract of Astragolus praegolus (e5s5: extraction 5, sample 5). Peaks: 1 , selenocystine; 2, Se-methyl-DL-selenocysteine; 3, DL-selenomethionine; 4 , Se-allyl-DL-selenocysteine; 5 , cis-Se-1-propenyl-DL-selenocysteine; 6 , trans-Se-1-propenyl-DL-selenocysteine; 7, DL-selenoethionine; 8 , Se-1-propyl-DL-selenocysteine

[38]. The HPLC chromatogram of the enzymatic extract of Astragolus praelongus (e5s5) is overlaid with the chromatogram of a selenoamino acid mixture in Fig. 3. Major compounds present in the sample are Se-methyl-DL-selenocysteine, DL-selenomethionine and traces of Se-allylDL-selenocysteine. The identification of the first peak as selenocystine is questionable due to the unsatisfactory separation power of the method at low retention times. Chromatographic modifications are under way to enable a more efficient separation, better sample recovery and shorter separation time.

As part of an ongoing study of the cancer chemopreventive activity of selenium, water extracts of selenium enriched plants were analyzed by HPLC-ICP-MS. Previous reports indicated several selenium species present in selenium enriched garlic [38] and more than 20 selenium species present in selenium enriched yeast [39]. Comparison of water extracts of selenium enriched garlic and onion, and three selenium enriched yeasts indicate selenium speciation to be sample dependent (Fig.4). The chromatogram in Fig. 4a indicates that the elution profile of selenium enriched garlic changes with the level of selenium present, for example as shown reproducibly in the 20-30 min region of the chromatogram. The samples enriched in selenium to levels of $100-300 \mu \mathrm{g} / \mathrm{g}$ Se have similar chromatographic profiles, the major selenium peak at 12 minutes being at present unidentified. Garlic enriched

in selenium to more than $1300 \mu \mathrm{g} / \mathrm{g}$ shows a distinctly different profile, the major selenium species eluting at $3.2 \mathrm{~min}$ being Se-methyl-DL-selenocysteine. Selenium enriched yeasts from different sources also show markedly different chromatographic profiles (Fig. 4b). The DL-selenoethionine present in these samples was a spiked chromatographic internal standard (IS). In general reproducibility of retention was better than $2 \%$, even allowing for possible small variations in the level of methanol present in the mobile phase. Whether these differences are due to fermentation conditions or result from the different total level of selenium present is unknown.

\section{Oxidation}

In an attempt to identify some of the unknown peaks in the selenium enriched samples, oxidation of the selenoamino acid standards with excess hydrogen peroxide was investigated. Chromatographic results of the oxidation are shown in Fig. 5. For each selenoamino acid oxidized a new selenium containing peak was produced. No original selenoamino acid peaks were found, indicating that all of the reactants were consumed. All of the selenoamino acid oxidation products eluted within the first six minutes. The earlier elution times are presumed to result from the increased polarity of the species arising from the addition of oxygen. The oxidation products of the cis/trans isomers of Se-1-propenyl-DL-selenocysteine (peaks 5a and 6a) coelute. Substitution of a $25 \mathrm{~cm} \mathrm{C18} \mathrm{column} \mathrm{for} \mathrm{the} 15 \mathrm{~cm} \mathrm{C8} \mathrm{col-}$ umn improved the resolution of the oxidation products of the cis/trans acids, indicating that the geometrical isomerism persisted unchanged during the oxidation process. In general, although the chromatographic results alone cannot confirm the products as selenoxides, they do indi- 
a
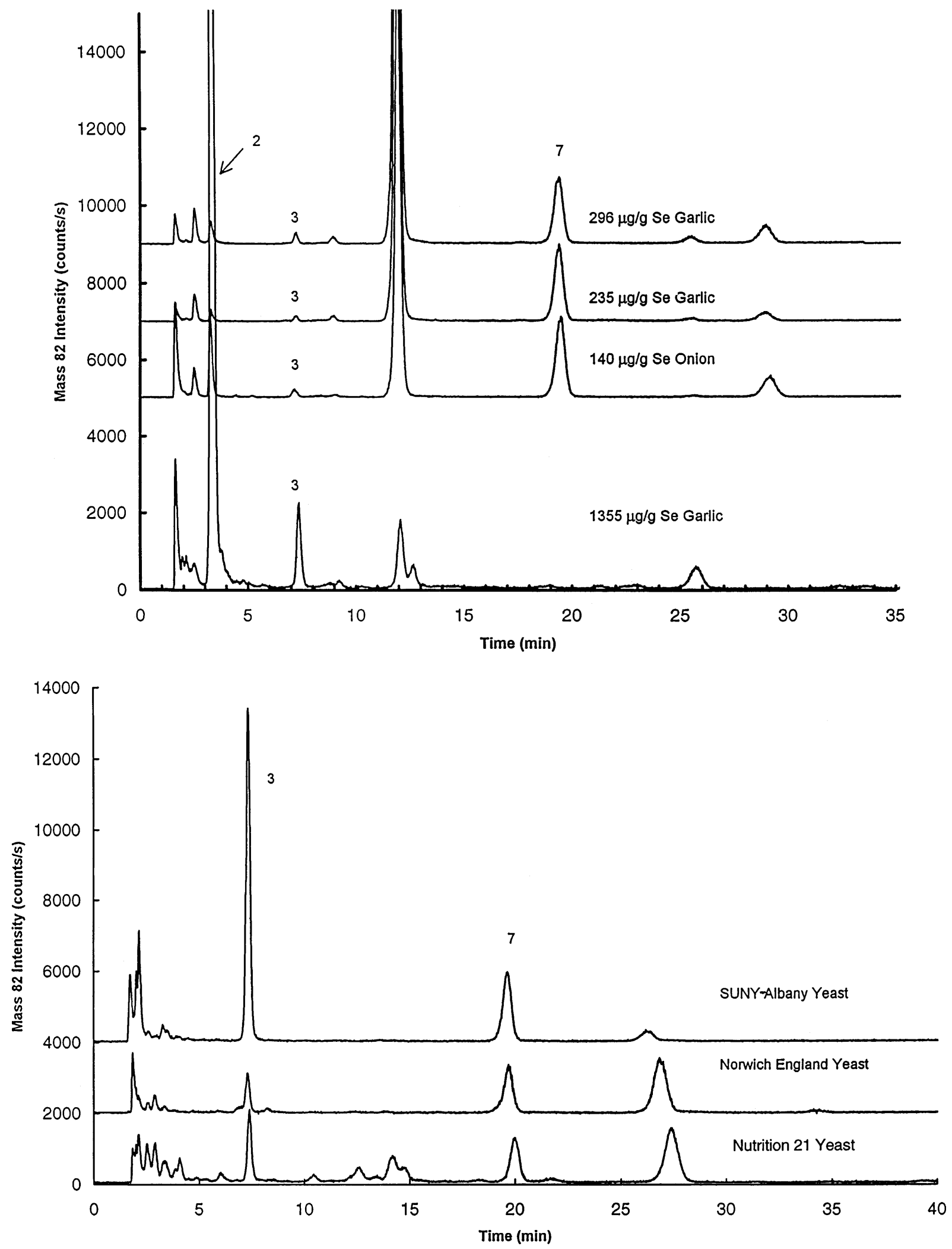

Fig. 4 a Comparison of chromatographic profiles of selenium enriched garlic and onion samples. Baseline offset for display purposes: $140 \mu \mathrm{g} / \mathrm{g}$ Se onion, baseline is at +5000 counts/s; $235 \mu \mathrm{g} / \mathrm{g}$ Se garlic, baseline is at +7000 counts/s; and $296 \mu \mathrm{g} / \mathrm{g} \mathrm{Se}$ garlic, baseline is at +9000 counts/s. b Comparison of chromatographic profiles of selenium enriched yeasts. Baseline offset for display purposes: Norwich England Yeast, baseline is at +2000 counts/s; SUNY Albany Yeast, baseline is at +4000 counts/s 
Fig. 5 Chromatograms of selenoamino acid standards and oxidized product after reaction with excess hydrogen peroxide. Baseline offset for display purposes: oxidized seleno amino acids baseline +1500 counts/s. See Fig. 3 for peak notation
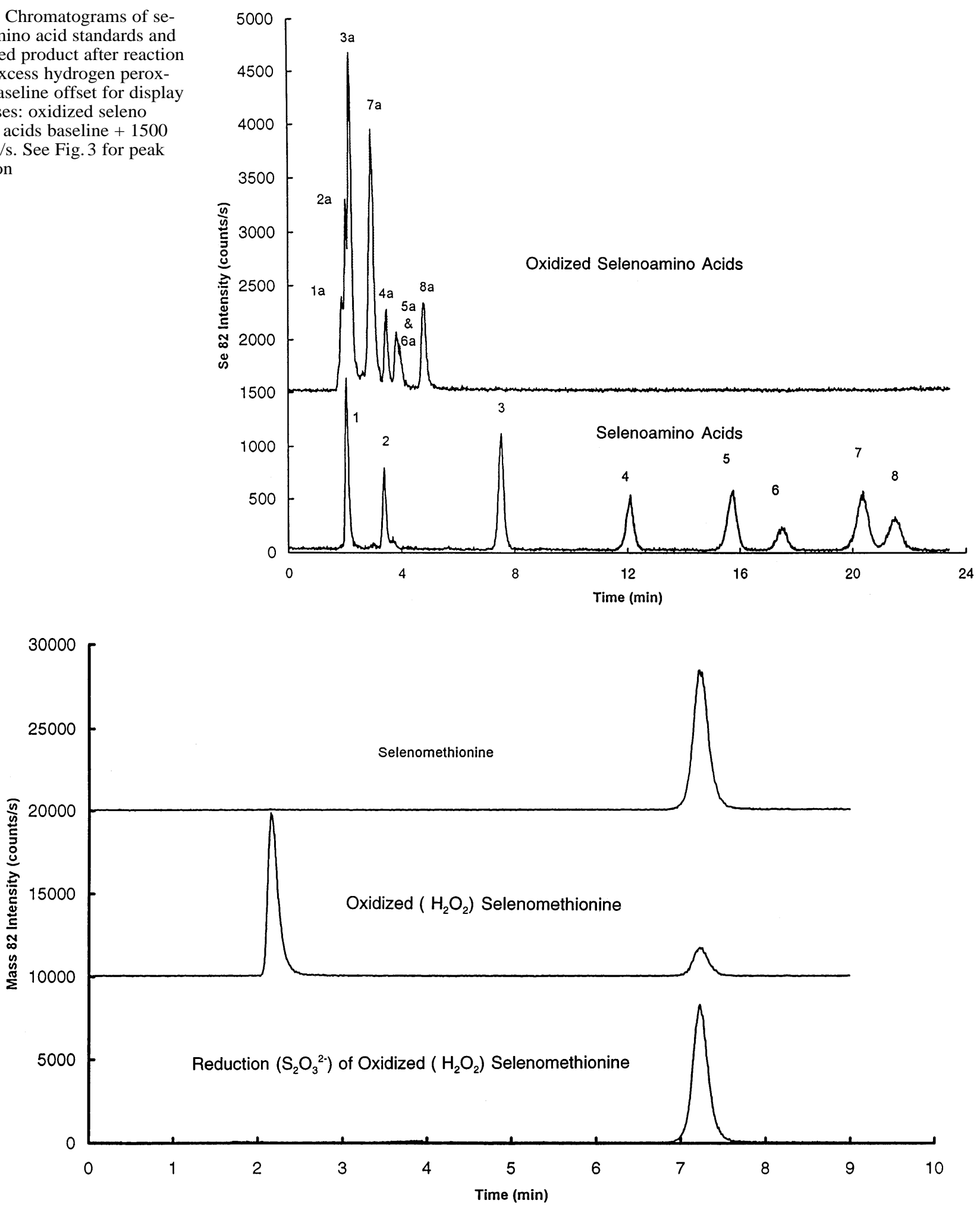

Fig. 6 Reversibility of oxidation of DL-selenomethionine monitored by chromatographic retention

cate the formation of more polar products which maintain the alkyl functionality of the selenoamino acids.

Proton NMR studies have shown the oxidation of selenomethionine to selenomethionine selenoxide by $\mathrm{Au}(\mathrm{III})$ in aqueous solution to be using thiosulfate as reductant [42]. The ability to reduce the oxidized selenomethionine product to selenomethionine would provide additional evidence of selenoxide formation. The oxidation of DL-selenomethionine with an approximately stoichiometric amount of hydrogen peroxide resulted in formation of a peak eluting at $2.2 \mathrm{~min}$, with some selenomethionine re- 


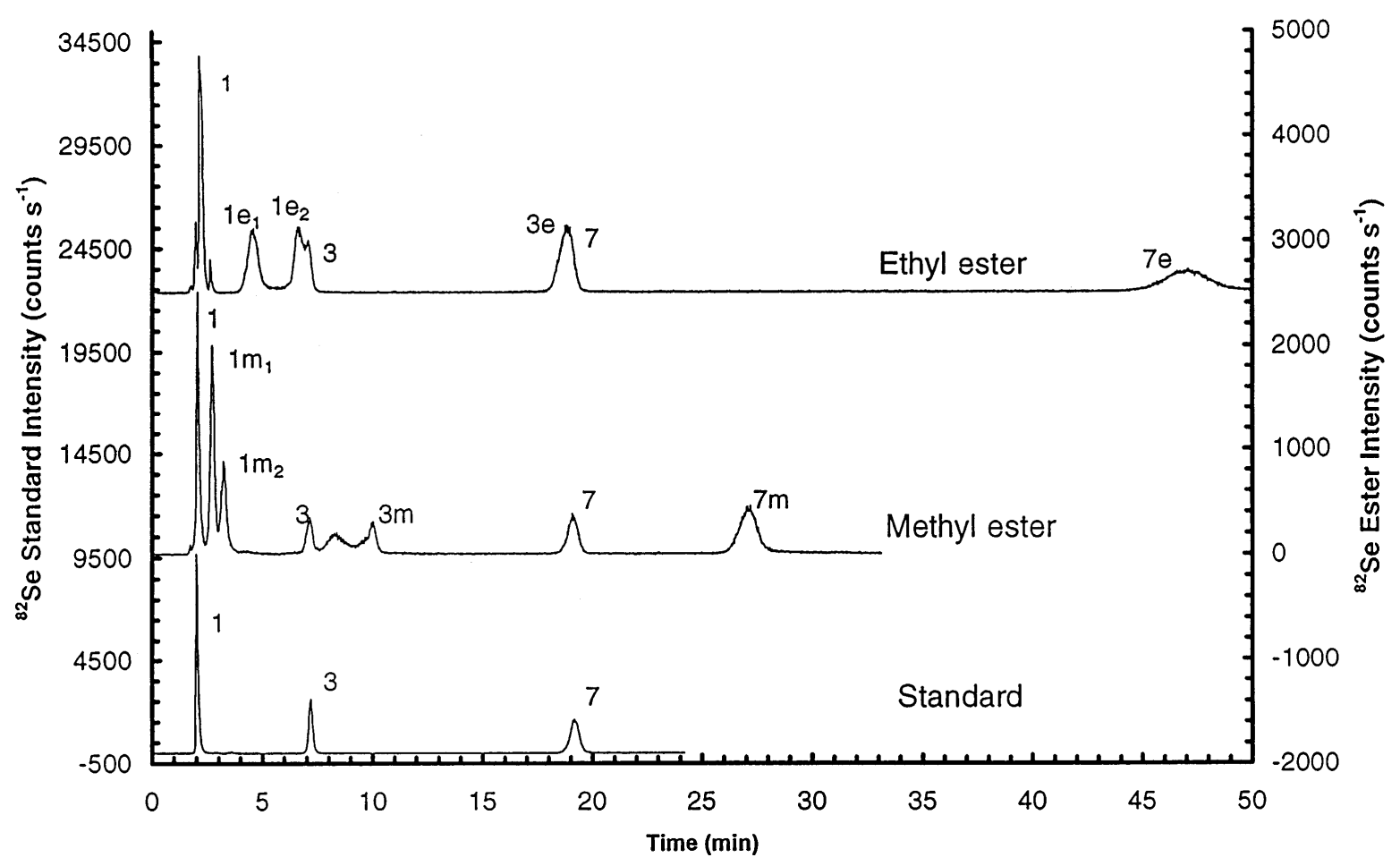

Fig. 7 Ion pair chromatogram of selenocystine (1), DL- selenomethionine (3), DL-selenoethionine (7) and their methyl- $\left(1 \mathrm{~m}_{1}, 1 \mathrm{~m}_{2}\right.$, $3 \mathrm{~m}, 7 \mathrm{~m})$ and ethyl-esters $\left(1 \mathrm{e}_{1}, 1 \mathrm{e}_{2}, 3 \mathrm{e}, 7 \mathrm{e}\right)$

maining (Fig.6). Upon addition of thiosulfate solution, the peak at 2.2 min disappears and the original selenomethionine peak is recovered, thus supporting the hypothesis of selenoxide formation. Further experiments, including LC-MS, are being performed to verify these conclusions.

\section{Esterification}

\section{Liquid chromatography}

Another approach to identify unknown peaks in the sample chromatograms is chemical derivatization. A simple derivatization of an amino acid is the esterification of the carboxyl group with an alcohol. The goal was to leave the amine group of the amino acid intact, as that part of the molecule is responsible for the ion pairing effect with the trifluoroacetic acid, while esterification of the carboxyl group was advantageous. The chromatogram resulting from the esterification of a mixture containing three selenoamino acids is presented in Fig. 7. The appearance of the presumed ester peaks in addition to the original amino acid peaks can be seen. As expected, esterified selenoamino acids are retained more strongly than the parent acids. The two peaks $\left(1 \mathrm{e}_{1}, 1 \mathrm{e}_{2}\right.$ and $\left.1 \mathrm{~m}_{1}, 1 \mathrm{~m}_{2}\right)$ resulting from the selenocystine are considered to result from the single and the double esterification of the two carboxyl groups present in selenocystine. The smaller second peak reflects the lower extent of the double esterification process.

\section{Gas chromatography}

In order to gain the most substantive analytical information for the identification and quantification of selenoamino acids and their reaction products, the application of alternative procedures is desirable. As noted earlier [18], selenoamino acids are readily derivatized by ethyl chloroformate to give volatile products suited to high resolution gas chromatography. Among the numerous choices for derivatization agents, ethyl chloroformate was used because it reacts with both the amino and the

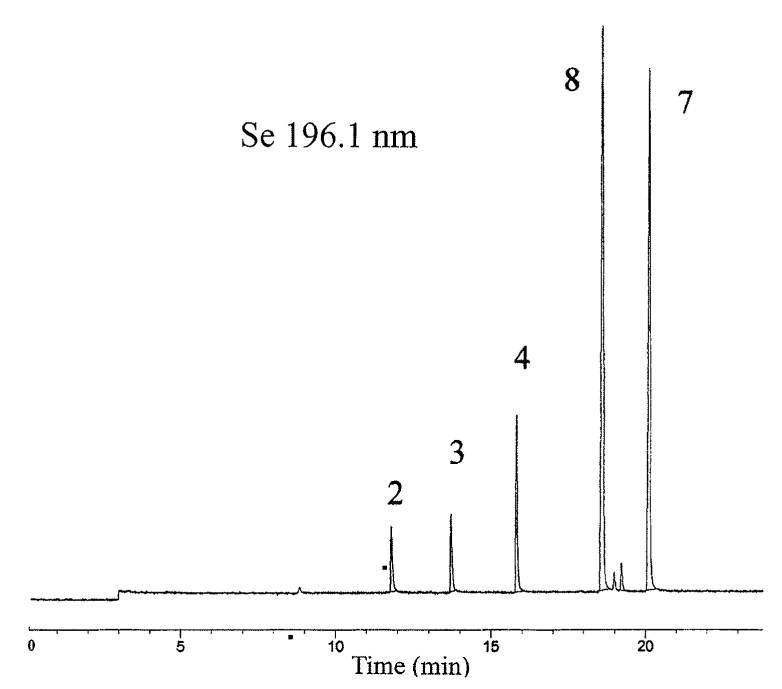

Fig. 8 GC-AED chromatogram of the standard selenoamino acid derivatives (annotated as in Fig. 3). (2), Se-methyl-DL-selenocysteine; (3), DL-selenomethionine; (4), Se-allyl-DL-selenocysteine; (7), DL-selenoethionine; (8), Se-1-propyl-DL-selenocysteine 
carboxylic acid residues in the amino acid, and also because the derivatization procedure is a one step reaction and occurs very rapidly. A procedure of less than $15 \mathrm{~min}$ duration provides a sample that is suitable for GC analysis. As can be seen in Fig. 8 which depicts a selenium specific chromatogram measured at $196 \mathrm{~nm}$, a single peak was obtained for each standard amino acid and excellent separation was observed. In this reference chromatogram, two minor peaks were not as yet identified. Work is in progress to quantify the percentage yield of the derivatization for the selenoamino acids and to implement this derivatization with plant samples having high selenium content, in order to independently characterize the selenium containing compounds identified using the HPLC method.

\section{Conclusion}

The complexity of the chemistry of selenium containing natural products calls for the application of sophisticated element specific separation methods to differentiate target analytes from background matrix species. Likewise reliable and reproducible methods for quantitative extraction and determination of total and species dependent selenium in varied matrices are essential for development. HPLC-ICP-MS, potentially reinforced by chloroformate derivatization GC-AED is effective for qualitative and quantitative separation and speciation of selenoamino acids and potentially their degradation and reaction products. The ability also to determine total selenium by ICPMS at different stages in the overall analytical protocol is essential in any quantitative study and adds confidence to conclusions on overall element content and reaction.

Acknowledgments This work was supported in part by the NIH (CA45164) and the NRI Competitive Grants Program/USDA (Award No. 96-355003351). The provision and maintenance of the Elan 5000 plasma source mass spectrometer by the Perkin-Elmer Corporation is gratefully acknowledged. The authors also thank Rhone Poulenc Rorer for providing support and for donation of the HP1090 liquid chromatograph, and MAC-MOD Analytical Inc. for providing the Zorbax columns. We thank Mark Tatro for providing the CFA-C reagent.

\section{References}

1. Alaejos MS, Romero CD (1995) Chem Rev 95: 227

2. Spallholz JE, Raferty A (1987) In: Combs GG, Levander OA, Spallholz JE, Oldfield JE (eds) Selenium in Biology and Medicine, New York, p 516

3. Heinz GH, Hoffman LJ, LeCaptain LJ (1996) Arch Environ Contam Toxicol 30: 93

4. Ip C, Ganther H (1992) In: Wattenberg L, Lipkin M, Boone CW, Kelloff GJ (eds) Cancer Chemoprevention. Boca Raton, p 479

5. Clark LC, Combs GF, Turnball BW, Slate EH, Chalker DK, Chow J, Davis LS, Glover RA, Graham DK, Gross EG, Krongrad A, Lesher JL, Park HK, Sanders BB, Smith CL, Taylor JR, Alberts DS, Allison RJ, Bradshaw JC, Curtis D, Deal DR, Dellasega M, Hendrix JD, Herlong JH, Hixson LJ, Knight F, Moore J, Rice JS, Rogers AI, Schuman B, Smith EH, Woodard JC (1996) J Amer Med Assoc 276: 1957
6. Young VR (1981) N Engl J Med 30: 1228

7. Sathe SK, Mason AC, Rodibaugh R, Weaver CM (1992) J Agric Food Chem 40: 2084

8. Hafeman DG, Sunde RA, Hoekstra WG (1974) J Nutrition 104: 580

9. Ganther H, Goudie C, Sunde ML, Kopecky MJ, Wagner, Hoekstra WG (1972) Science 175: 1122

10. Dickson RC, Tomlinson RH (1967) Clin Chim Acta 16: 311

11. Qi YG, Hu ZR, Zuang SS (1981) International Conference on Nutrition. Tianjin, China, June

12. Spare CG, Virtanen AI (1964) Acta Chem Scand 18: 281

13. Apte SC, Howard AG (1986) J Anal At Spectrom 1: 379

14. Jiang SG, Robberecht H, Adams F (1989) Appl Organomet Chem 3: 99

15. Cai XJ, Uden PC, Block E, Zhang X, Sullivan JJ, Quimby BD (1994) Anal Proc 31: 325

16. Cai XJ, Uden PC, Block E, Zhang X, Sullivan JJ, Quimby BD (1994) J Agric Food Chem 42: 2085

17. Cai XJ, Block E, Uden PC, Zhang X, Sullivan JJ, Quimby BD (1995) J Agric Food Chem 43: 1751

18. Cai XJ, Block E, Uden PC, Zhang X, Sullivan JJ, Quimby BD (1995) J Agric Food Chem 43: 1754

19. Block E, Calvey EM, Gillies CW, Gillies JZ, Uden PC (1997) Peeling the Onion: Organosulfur and -Selenium Phytochemicals in Genus Allium Plants. In: Johns T, Romeo J (eds) Recent Advances in Phytochemistry, Vol 31 Functionality of Food Phytochemicals. Plenum, New York, p 17

20. Fenwick GR, Hanely (1985) CRC Critical Reviews in Food Science and Nutrition 22: 273

21. Wrench JJ (1978) Marine Biology 49:231

22. Bottino NR, Banks CH, Irgolic KJ, Micks P, Wheeler AE, Zingaro RA (1984) Phytochemistry 23: 2445

23. Laborda F, de Loos-Vollebregt MTC, de Galan L (1992) Spectrochim Acta Part B 46: 1089

24. Laborda F, Chakraborti D, Mir JM, Castillo JR (1993) J Anal At Spectrom 8: 43

25. Cobo-Fernandez MG, Palacios MA, Chakraborti D, Quevauviller P, Camara C (1995) Fresenius J Anal Chem 351: 438

26. Potin-Gautier M, Boucharat C, Astruc A, Astruc M (1993) Appl Organomet Chem 7: 593

27. Sanz-Medel A, Aizpun B, Marchante JM, Segovia E, Fernandez ML, Blanco E (1994) J Chromatogr 683: 233

28. Schlegel D, Mattusch J, Dittrich K (1994) J Chromatogr 683: 261

29. Matni G, Azani R, Van Calsteren MR, Bissonnette MC, Blais JS (1995) Analyst 120: 395

30. Colon LA, Barry EF (1991) J High Resol Chromatogr 14: 609

31. Huyghues-Despointes A, Momplaisir GM, Blais JS, Marshall WD (1991) Chromatographia 31: 481

32. Blaise JS, Huyghues-Despointes A, Momplaisir GM, Marshall WD (1991) J Anal At Spectrom 6: 225

33. Quijano MA, Gutierrez M, Perez-Conde C, Camara CJ (1996) J Anal At Spectrom 11: 407

34. Ge H, Cai XJ, Tyson JF, Uden PC, Denoyer ER, Block E (1996) Anal Comm 33: 279

35. Crews HM, Clarke PA, Lewis J, Owen LM, Strutt PR, Izquierdo A (1996) J Anal At Spectrom 11: 1177

36. Olivas R, Donard OFX, Gilon N, Potin-Gautier M (1996) J Anal At Spectrom 11: 1171

37. Pedersen GA, Larsen EH (1997) Fresenius J Anal Chem 358: 591

38. Bird SM, Uden PC, Tyson JF, Block E, Denoyer E (1997) J Anal At Spectrom 12:785

39. Bird SM, Ge H, Uden, PC, Tyson JF, Block E, Denoyer E (1997) J Chromatogr 789:249

40. Husek P (1991) J Chromatogr 552: 289

41. Krushevska A, Kotrebai M, Barnes RM (1996) Fresenius J Anal Chem 355: 793

42. Isab AA (1983) Inorganica Chimica Acta 80:L3 